\title{
PERBEDAAN KEMAMPUAN BERBICARA ANAK YANG DIASUH ORANG TUA SENDIRI DAN YANG DIASUH OLEH PENGASUH (STUDI KASUS PADA 2 ANAK TETANGGA)
}

\author{
Yuli Astrina Saria, Ahmad Fachrurrazi ${ }^{\text {b }}$ \\ aPendidik Kelompok Bermain Tatsbiyatul Hidayah, Taman-Sidoarjo \\ bProgram Studi PGPAUD FKIP Universitas PGRI Adi Buana Surabaya \\ e-mail: yustrinsari86@yahoo.com
}

\begin{abstract}
This research is motivated by differences in parenting that can affect the development of children aged 2-3 years, especially in terms of the ability to speak. Based on observations made with regard to language and talk of children, are still limited in pronunciation and speech fluency. Through speaking, the child can communicate, convey thoughts, ideas and feelings so that children are able to interact and build relationships social surroundings. Therefore, the need for stimulation that can increase the child's ability to speak, one of them through the method of conversing. The purpose of this study was to describe the differences in the ability to speak of the children within their own and with cared for by a caregiver. This is a qualitative research with a case study approach. The technique used an expose facto. Expose facto selected, because the cases studied individual. The results indicate differences in the ability to speak between children raised by their own parents and those cared for by caregivers. The children raised by caregivers show a better development of speech skills than children raised by their own parents.
\end{abstract}

Keywords: Children's Ability to speak, cared for by own parent and cared for by caregiver

\section{PENDAHULUAN}

Bagi orang tua, anak merupakan harapan dimasa mendatang. Setiap orangtua hampir tidak ada yang membantah bahwa anak adalah investasi yang tak ternilai harganya. Kesuksesan anak di masa mendatang adalah kebanggan bagi orangtuanya. Madyawati (2015:4)

Lima tahun pertama, menurut Hasan (2012:29) yang disebut dengan The Golden Year, seorang anak mempunyai potensi yang sangat besar untuk berkembang. Pada usia ini, 90\% dari fisik otak anak sudah terbentuk. Di masa-masa inilah, anak seyogianya mulai diarahkan. Masa keemasan ini tidak akan terjadi dua kali. Sebagai orang tua yang proaktif, orang tua hendaknya memperhatikan hal- hal yang berkenaan dengan perkembangan sang buah hati, yang merupakan amanat Tuhan.

Menurut Benson dalam Zubaidah (2016:6) masalah bahasa (language) dan bicara (speech) adalah dua pengertian yang tidak dapat dipisahkan satu dengan yang lain. Kedua kemampuan tersebut juga sangat berkaitan dengan proses berfikir (thought). Apakah hubungannya dengan perkembangan bahasa anak dalam pembicaraan ini. Masalah perkembangan anak, yang sering dipersoalkan adalah tentang "kapankah anak menguasai kemampuan bahasa, dan kapankah anak menguasai kemampuan bicara?" Ada pendapat yang mengatakan bahwa berbicara lebih dahulu dikuasai baru diikuti bahasa dan ada pula yang mengatakan bahwa antara bahasa dan bicara 
berkembang bersama-sama. Pendapat pertama dijelaskan oleh Tarmansyah (dalam Zubaidah, 1996:33) bahwa bahasa berkembang terlebih dahulu baru diikuti bicara. Dikatakan lebih lanjut bahwa masalah tersebut dapat dibuktikan dengan kurangnya atau tidak dimilikinya perbendaharaan kata atau kosakata pada anak, sehingga anak tidak dapat berbicara.

Menurut Hasan (2013:49) Tiga tahun pertama adalah merupakan masa yang sangat menentukan dalam kehidupan anak. Mungkin banyak yang bertanya, "Mengapa tiga tahun pertama sangat menentukan dalam kehidupan anak?" Hal ini dikarenakan bagian terpenting dalam tubuh manusia adalah otak. Otak tumbuh sangat pesat pada awal kehidupan dan akan mencapai $70-80 \%$ pada tiga tahun pertama. Oleh karena itu, jika seseorang menginginkan putera puterinya tumbuh dengan kondisi yang terbaik, maka orang tua harus menginfestasikan waktunya pada tiga tahun pertama ini. Jika orang tua memngabaikan rentang waktu tiga tahun pertama ini, maka anak tidak akan berkembang dengan maksimal dan anak akan menjadi anak yang biasa- biasa saja.

Menurut Suhartono (2005:14) dengan memperhatikan peranan bahasa bagi anak, yang perlu dipikirkan adalah bagaimana peranan bahasa itu dapat diterapkan oleh anak setiap hari dalam pergaulannya secara baik dan maksimal. Artinya, bila kita mengetahui anak itu pendiam langkah yanng harus kita lakukan adalah bagaimana mengajak anak itu untuk berbicara. Bukan sebaliknya, kita yang banyak berbicara sedangkan anak disuruh mendengarkan saja.

Kemampuan berbicara akan mulai diproses sejak anak usia dini bahkan sebelum anak lahir pun biasanya sering kali dilakukan terapi berbicara dengan anak dalam kandungan. Berbicara adalah salah satu indikator perkembangan anak. Anak yang bisa bicara lancar maka menandakan bahwa anak tersebut memiliki perkembangan yang baik. Begitu pula sebaliknya ketika anak terlambat berbicara maka anak perlu diwaspadai. Tujuannya adalah untuk memberikan stimulasi yang baik dan benar kepada anak agar anak cepat berbicara. Wardiah (2014:3).

Lebih lanjut Wardiah mengungkapkan betapa pentingnya keterampilan berbicara dikuasai anak, sebab berbicara bukan hanya sekedar pengucapan kata atau bunyi saja tetapi dengan berbicara anak dapat mengungkapkan kebutuhan dan keinginannya, mendapat perhatian dari orang lain, menjalin hubungan sosial sekaligus penilaian sosial dari orang lain, dapat menilai diri sendiri berdasarkan masukan atau penilaian orang lain terhadap dirinya, serta mempengaruhi perasaan, pikiran dan perilaku orang lain. Penguasaan bahasa khususnya penguasaan keterampilan berbicara anak usia dini dapat diperoleh melalui pembelajaran. Pembelajaran bahasa mengacu pada pengumpulan pengetahuan bahasa melalui sesuatu yang disadari oleh pembelajar bahasa.

Pendidikan Anak Usia Dini (PAUD) adalah pendidikan yang memberikan pengasuhan perwatan, dan pelayanan kepada anak usia lahir sampai enam tahun. Siibak dan Vinter dalam Madyawati (2015:3). Dengan pengertian tersebut, dapat dipahami bahwa pengasuhan anak yang dimaksud adalah kepemimpinan dan bimbingan yang dilakukan terhadap anak yang berkaitan dengan kepentingan hidupnya. Dan dalam studi kasus 2 anak tetangga yang diamati terdapat dua 
pola asuh yang digunakan, yaitu pola asuh mandiri (diasuh oleh orang tua sendiri) dan pola asuh pengasuh.

Fokus permasalahan dalam studi kasus ini adalah "adakah perbedaan kemampuan berbicara pada anak yang diasuh oleh orang tua sendiri dengan yang diasuh oleh pengasuh, dan bagaimana peberdaan di antara keduanya?"

\section{METODE PENELITIAN}

Jenis penelitian ini adalah penelitian kualitatif dengan pendekatan studi kasus, teknik yang digunakan dalam pendekatan studi kasus ini adalah expose facto (Muhadjir, 1991). Expose facto dipilih sebagai teknik dalam pendekatan ini karena kasus yang diteliti bersifat individual (Muhadjir, 1991).

Data dan Sumber Data

1. Anak yang diasuh orang tua sendiri:

Nama : Jonathan Verdinan

Umur : 2 Tahun 3 bulan

Nama orang tua: Sari Verdinan (38 tahun)

2. Anak yang diasuh oleh pengasuh

Nama : Kenzo Alfaro Raziq Hanan

Umur : 2 Tahun 6 bulan

Nama pengasuh : Rukmayanti (38 tahun)

Teknik pengumpulan data yang digunakan penulis dalam penelitian ini meliputi observasi partisipatif dan catatan lapangan. "Dengan observasi partisipatif di lapangan peneliti akan lebih mampu memahami konteks data dalam keseluruhan situasi sosial, jadi akan dapat diperoleh pandangan yang holistik atau menyeluruh." (Sugiyono, 2010:67). Sedangkan intrumen yang digunakan adalah Lembar Observasi Partisipatif.

Data dianalisis dengan teknik analisis deskriptif kualitatif dengan mengacu pada teori
Miles and Huberman (1992), Sugiono (2010) dengan aktivitas analisis data meliputi data reduction, data display, dan conclusion drawing/verification.

\section{HASIL PENELITIAN}

Hasil penelitian terhadap 4 (empat) indikator kemampuan berbicara yang diamati dapat digambarkan sebagai berikut.

Tabel 1. Kemampuan berbicara sumber data 1

Nama : Jonathan Verdinan

Umur : 2 Tahun 3 bulan

\begin{tabular}{llcccc}
\hline NO & \multicolumn{1}{c}{ Indikator } & \multicolumn{4}{c}{ Frekuensi Capaian } \\
& Perkembangan \\
\hline 1. & $\begin{array}{l}\text { Kelancaran } \\
\text { Ucapan }\end{array}$ & 6 & 6 & 4 & - \\
2. $\quad \begin{array}{l}\text { Kejelasan } \\
\text { Ucapan }\end{array}$ & 4 & 6 & 4 & 2 \\
3. $\quad \begin{array}{l}\text { Mengerti } \\
\text { Perintah } \\
\text { sederhana } \\
\text { Menyebutkan }\end{array}$ & 5 & 7 & 3 & 1 \\
& $\begin{array}{l}\text { nama benda di } \\
\text { sekitarnya }\end{array}$ & 4 & 6 & 4 & 2 \\
\hline TOTAL & 19 & 25 & 15 & 5
\end{tabular}

Keterangan : Pengamatan dilakukan sebanyak 16 kali

BB : Belum Berkembang

MB : Mulai Berkembang

BSH : Berkembang Sesuai Harapan

BSB : Berkembang Sangat Baik

Tabel 2. kemampuan berbicara sumber data 2

Nama : Kenzo Alfaro Raziq Hanan

Umur : 2 Tahun 6 bulan

\begin{tabular}{|c|c|c|c|c|c|}
\hline \multirow[t]{2}{*}{$\mathrm{NO}$} & \multirow[t]{2}{*}{ Indikator } & \multicolumn{4}{|c|}{$\begin{array}{c}\text { Frekuensi Capaian } \\
\text { Perkembangan }\end{array}$} \\
\hline & & $\mathrm{BB}$ & $\mathrm{MB}$ & $\mathrm{BSH}$ & BSB \\
\hline 1. & $\begin{array}{l}\text { Kelancaran } \\
\text { Ucapan }\end{array}$ & 2 & 8 & 4 & 2 \\
\hline 2. & $\begin{array}{l}\text { Kejelasan } \\
\text { Ucapan }\end{array}$ & 4 & 6 & 4 & 2 \\
\hline 3. & Mengerti & & & & \\
\hline & $\begin{array}{l}\text { Perintah } \\
\text { sederhana }\end{array}$ & 4 & 5 & 4 & 3 \\
\hline 4. & $\begin{array}{l}\text { Menyebutkan } \\
\text { nama benda di } \\
\text { sekitarnya }\end{array}$ & 2 & 3 & 6 & 5 \\
\hline TOT & & 12 & 22 & 18 & 12 \\
\hline
\end{tabular}

Keterangan : Pengamatan dilakukan sebanyak 16 kali

BB : Belum Berkembang

MB : Mulai Berkembang 
BSH : Berkembang Sesuai Harapan

BSB : Berkembang Sangat Baik

Sedangkan peran orang tua dan pengasuh sebagai faktor pendukung perkembangan kemampuan berbicara anak dapat digambarkan sebagai berikut.

Tabel 3. Peran orang tua dalam melatih kemampuan berbicara anak.

Nama orang tua : Sari Verdinan (38 tahun)

\begin{tabular}{|c|c|c|c|c|c|}
\hline $\mathrm{NO}$ & $\begin{array}{l}\text { Pemberian stimulus } \\
\text { pada balita agar bisa } \\
\text { berbicara }\end{array}$ & $\mathrm{TP}$ & $\mathrm{P}$ & $\mathrm{S}$ & SS \\
\hline 1. & $\begin{array}{l}\text { Bernyanyi dengan } \\
\text { berirama dan dengan } \\
\text { gerakan. }\end{array}$ & 3 & 5 & 6 & 2 \\
\hline 2. & $\begin{array}{l}\text { Melakukan } \\
\text { pengulangan }\end{array}$ & 3 & 4 & 3 & 6 \\
\hline 3. & $\begin{array}{l}\text { Melatih anak untuk } \\
\text { melakukan pilihan, }\end{array}$ & 2 & 5 & 7 & 2 \\
\hline 4. & $\begin{array}{l}\text { Memberikan banyak } \\
\text { kesempatan }\end{array}$ & 3 & 5 & 7 & 1 \\
\hline 5. & $\begin{array}{l}\text { Cara memperbaiki } \\
\text { kesalahan berbahasa }\end{array}$ & 4 & 7 & 4 & 1 \\
\hline 6. & $\begin{array}{l}\text { Kontak mata dengan } \\
\text { mulut }\end{array}$ & 5 & 4 & 5 & 2 \\
\hline 7. & $\begin{array}{l}\text { Mendampingi anak } \\
\text { dalam menonton TV } \\
\text { dan film-film ceria } \\
\text { menyenangkan. }\end{array}$ & 5 & 2 & 8 & 1 \\
\hline \multicolumn{6}{|c|}{$\begin{array}{ccccc}\text { TOTAL } & 25 & 32 & 40 & 15 \\
\text { Keterangan : Pengamatan dilakukan sebanyak } & 16 & \text { kali }\end{array}$} \\
\hline $\begin{array}{l}\text { Keter } \\
\text { TP } \\
\text { P } \\
\text { S } \\
\text { SS }\end{array}$ & $\begin{array}{l}\text { ngan : Pengamatan dila } \\
\text { : Tidak Pernah } \\
\text { : Pernah } \\
\text { : Sering } \\
\text { : Sering Sekali }\end{array}$ & kan s & bany & $\mathrm{k} 10$ & kali \\
\hline
\end{tabular}

Tabel 4. Peran pengasuh dalam melatih kemampuan Berbicara anak

Nama Pengasuh : Rukmayanti (38 tahun)

\begin{tabular}{lllll}
\hline NO $\quad \begin{array}{l}\text { Pemberian stimulus } \\
\text { pada balita agar bisa } \\
\text { berbicara }\end{array}$ & TP & P & S & SS \\
\hline 1. $\quad \begin{array}{l}\text { Bernyanyi dengan } \\
\text { berirama dan dengan } \\
\text { gerakan. }\end{array}$ & 3 & 4 & 7 & 2 \\
2. $\quad \begin{array}{l}\text { Melakukan } \\
\text { pengulangan }\end{array}$ & 1 & 4 & 8 & 3 \\
3. $\quad \begin{array}{l}\text { Melatih anak untuk } \\
\text { melakukan pilihan, }\end{array}$ & - & 5 & 8 & 3 \\
4. $\quad \begin{array}{l}\text { Memberikan banyak } \\
\text { kesempatan } \\
\text { Cara memperbaiki }\end{array}$ & - & 5 & 7 & 4 \\
6. $\quad \begin{array}{l}\text { kesalahan berbahasa } \\
\text { Kontak mata dengan } \\
\text { mulut }\end{array}$ & 2 & 3 & 9 & 2 \\
Mendampingi anak & 3 & 4 & 6 & 3 \\
\hline
\end{tabular}

dan film-film ceria

menyenangkan.

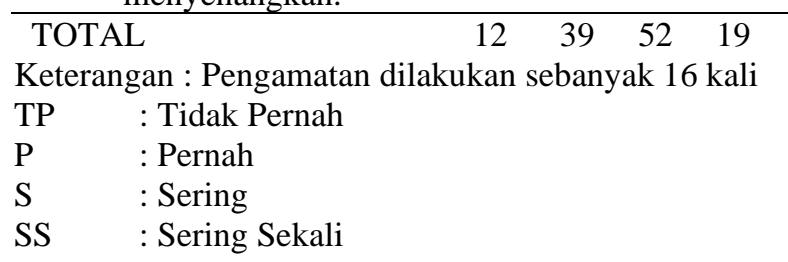

\section{PEMBAHASAN}

Dari data tabel 1 dan 2 dapat diketahui perbedaan capaian perkembangan kemampuan berbicara anak yang diasuh oleh orang tua sendiri dengan anak yang diasuh oleh pengasuh. Pembahasan difokuskan hanya pada capaian perkembangan Mulai Berkembang (MB), Berkembang Sesuai Harapan (BSH) dan Berkembang Sangat Baik (BSB). Sedangkan capaian perkembangan Belum Berkembang (BB) diabaikan.

Capaian perkembangan mulai berkembang perbandingannya adalah 25:22. Pada tahap perkembangan ini anak yang diasuh oleh orang tua sendiri sedikit lebih baik daripada anak yang diasuh oleh pengasuh. Tetapi pada capaian perkembangan berkembang sesuai harapan anak yang diasuh oleh orang tua tidak lebih baik daripada anak yang diasuh oleh pengasuh. Perbandingan total skornya adalah 15:18. Sedangkan pada capaian perkembangan berkembang sangat baik anak yang diasuh oleh pengasuh menunjukkan perkembangan yang lebih baik daripada anak yang diasuh oleh orang tua sendiri, dengan perbandingan total skor 12:5. Perbedaan yang cukup jauh.

Berdasarkan data di atas dapat dikatakan anak yang diasuh oleh orang tua dan yang diasuh oleh pengasuh sama-sama menunjukkan kecerendungan Mulai Berkembang (MB). Akan tetapi anak yang diasuh oleh pengasuh 
menunjukkan kecerendungan lebih baik dalam kemampuan berbicara dan kelancaran berbicara dibandingkan dengan anak yang diasuh sendiri oleh orangtuanya.

Jika dilihat dari peran orang tua dan pengasuh dalam membantu melatih kemampuan berbicara anak nampaknya intensitas (tingkat kesringan) bantuan dalam pemberian stimulus merupakan faktor yang mempengaruhi perkembangan kemampuan berbicara anak. Dari tabel 3 dan 4 di atas dapat diketahui perbedaan intensitas pemberian stimulus antara orang tua dengan pengasuh. Dari tujuh indikator stimulus secara umum pengasuh lebih sering bahkan sangat sering memberikan stimulus kepada anak daripada orang tua yang memberikan stimulus itu.

Perbadingan antara pengasuh dan orang tua dalam pemberian stimulus untuk menunjang kemampuan berbicara anak adalah 52:40 untuk tingkat sering, dan 19:15 untuk tingkat sangat sering. Hal ini menggambarkan bahwa intensitas komunikasi dengan anak dapat mempengaruhi perkembangan kemampuan berbicara anak. Hal ini sejalan dengan apa yang dituliskan Suhartono (2005:20) bahwa berbicara secara umum dapat diartikan suatu penyampaian maksud (ide, pikiran, gagasan atau isi hati) seseorang kepada orang lain dengan menggunakan bahasa lisan sehingga maksud tersebut dapat dipahami. Di samping itu tingkat intensitas komunikasi ini juga akan mempengaruhi keterampilan berbicara yang sangat penting dikuasai anak, sebab berbicara bukan hanya sekedar pengucapan kata atau bunyi saja tetapi dengan berbicara anak dapat mengungkapkan kebutuhan dan keinginannya, mendapat perhatian dari orang lain, menjalin hubungan sosial sekaligus penilaian sosial dari orang lain, dapat menilai diri sendiri berdasarkan masukan atau penilaian orang lain terhadap dirinya, serta mempengaruhi perasaan, pikiran dan perilaku orang lain.

\section{SIMPULAN DAN SARAN}

\subsection{Simpulan}

Bertolak dari fokus permasalahan dengan dilandasi uraian pembahasan berdasarkan data hasil penelitian dapat disimpulkan bahwa ada perbedaan kemampuan berbicara antara anak yang diasuh oleh orang tua sendiri dengan yang diasuh oleh pengasuh. Anak yang diasuh oleh pengasuh menunjukkan kecerendungan memiliki kemampuan berbicara lebih baik dari pada anak yang diasuh oleh orangtua. Perbedaan kemampuan berbicara antara anak yang diasuh oleh pengasuh dengan anak yang diasuh orang tua sendiri adalah dalam hal pengucapan dan kelancaran berbicara anak yang diasuh oleh pengasuh cenderung lebih baik dari pada anak yang diasuh oleh orang tua.

\subsection{Saran}

Berdasarkan hasil penelitian yang telah dilakukan maka, diuraikan beberapa implikasi untuk pihak yang terkait sebagai berikut.

a. Bagi Pengasuh

Diharapkan dapat wawasan tentang pola asuh, sehingga mampu membantu perkembangan kemampuan berbicara pada anak secara optimal b. Bagi Orang tua

Diharapkan meningkatkan intensitas komunikasi dengan anak agar anak kemampuan berbicara anak dapat lebih dikembangkan. Sealin itu komunikasi yang intensif akan dapat membantu mengoptimalkan perkembangan anak secara umum. 


\section{REFERENSI}

Hasan, Maimunah. (2009). Pendidikan Anak Usia Dini. Jogjakarta: Penerbit Dina Press.

Madyawati, Lilis. (2005). Strategi Pengembangan Bahasa Pada Anak. Jakarta: Penerbit Prenada Media Grup.

Miles, Mathew B dan Huberman, A. Michael. (1992). Analisis Data Kualitatif. terjemahan oleh Tjetjep Rohendi Rohidi. Jakarta: UIPress.

Muhadjir, Noeng. (1991). Metodologi Penelitian Kualitatif. Yogyakarta: Penerbit Rake Sarasin P.O Box 83 .

Sugiyono. (2010). Metode Penelitian Pendekatan Metode Kuantitaitf, Kualitatif, dan R \& D. Bandung: Alfabeta.

Suhartono. (2005). Pengembangan Ketrampilan Berbicara. Departemen Pendidikan Nasional Direktorat Jendral Pendidikan Tinggi, Direktorat Pembinaan Pendidikan Tenaga Kependidikan Dan Ketenagaan Perguruan Tinggi Jakarta.

Wardiah, Dessy. Psikolinguistik Dalam Kemampuan Berbicara Pada Anak Usia Dini. Tersedia dalam: http://eprints.uny.ac.id/8074/3/bab\%202\%20\%2008111241037.pdf. Diakses 26 Juli 2016.

Zubaidah, Enny. (2016). Pengembangan Bahasa Anak Usia Dini Pendidikan Dasar dan Pra Sekolah. Fakultas Ilmu Pendidikan Universitas Negeri Yogyakarta. 